ARTICLE

Received 4 Feb 2017 | Accepted 30 May 2017 | Published 19 Jul 2017

DOI: $10.1038 /$ ncomms16115

OPEN

\title{
Accumulating the hydride state in the catalytic cycle of [FeFe]-hydrogenases
}

\author{
Martin Winkler ${ }^{1}$, Moritz Senger ${ }^{2}$, Jifu Duan ${ }^{1}$, Julian Esselborn ${ }^{1}$, Florian Wittkamp ${ }^{3}$, Eckhard Hofmann ${ }^{4}$, \\ Ulf-Peter Apfel ${ }^{3}$, Sven Timo Stripp ${ }^{2} \&$ Thomas Happe ${ }^{1}$
}

$\mathrm{H}_{2}$ turnover at the [FeFe]-hydrogenase cofactor (H-cluster) is assumed to follow a reversible heterolytic mechanism, first yielding a proton and a hydrido-species which again is doubleoxidized to release another proton. Three of the four presumed catalytic intermediates $\left(\mathrm{H}_{\mathrm{ox}}, \mathrm{H}_{\mathrm{red}} / \mathrm{H}_{\text {red }}\right.$ and $\left.\mathrm{H}_{\text {sred }}\right)$ were characterized, using various spectroscopic techniques. However, in catalytically active enzyme, the state containing the hydrido-species, which is eponymous for the proposed heterolytic mechanism, has yet only been speculated about. We use different strategies to trap and spectroscopically characterize this transient hydride state $\left(\mathrm{H}_{\text {hyd }}\right)$ for three wild-type [FeFe]-hydrogenases. Applying a novel set-up for real-time attenuated total-reflection Fourier-transform infrared spectroscopy, we monitor compositional changes in the state-specific infrared signatures of [FeFe]-hydrogenases, varying buffer $\mathrm{pH}$ and gas composition. We selectively enrich the equilibrium concentration of $H_{\text {hyd, }}$ applying Le Chatelier's principle by simultaneously increasing substrate and product concentrations $\left(\mathrm{H}_{2} / \mathrm{H}^{+}\right)$. Site-directed manipulation, targeting either the proton-transfer pathway or the adt ligand, significantly enhances $\mathrm{H}_{\text {hyd }}$ accumulation independent of $\mathrm{pH}$.

\footnotetext{
${ }^{1}$ AG Photobiotechnologie, Lehrstuhl für Biochemie der Pflanzen, Fakultät für Biologie und Biotechnologie, Ruhr-Universität Bochum, Universitätsstraße 150 44801 Bochum, Germany. ${ }^{2}$ Experimental Molecular Biophysics, Department of Physics, Freie Universität Berlin, Arnimallee 14, 14195 Berlin, Germany.

${ }^{3}$ Fakultät für Chemie und Biochemie, Lehrstuhl für Anorganische Chemie I/Bioanorganische Chemie, Ruhr-Universität Bochum, Universitätsstraße 150,44801 Bochum, Germany. ${ }^{4}$ AG Proteinkristallographie, Lehrstuhl für Biophysik, Fakultät für Biologie und Biotechnologie, Ruhr-Universität Bochum, Universitätsstraße 150, 44801 Bochum, Germany. Correspondence and requests for materials should be addressed to S.T.S. (email: sven.stripp@fu-berlin.de) or to T.H. (email: thomas.happe@ruhr-uni-bochum.de).
} 
ydrogen $\left(\mathrm{H}_{2}\right)$ turnover in $[\mathrm{FeFe}]$-hydrogenases is proposed to occur at the distal iron site $\left(\mathrm{Fe}_{\mathrm{d}}\right)$ of the [2Fe2S] moiety $\left(2 \mathrm{Fe}_{\mathrm{H}}\right)$, which is part of the H-cluster ${ }^{1}$. The distal iron ion exchanges protons with a conserved proton-transfer pathway $(\mathrm{PTP})^{2,3}$ via an azadithiolate ligand (adt) that bridges both iron sites (Fig. 1) ${ }^{4,5}$. Different redox states of the H-cluster can be distinguished by the unique infrared vibrational signatures of the two $\mathrm{CN}^{-}$and three $\mathrm{CO}$ ligands at the $2 \mathrm{Fe}_{\mathrm{H}}$ moiety. To tailor $[\mathrm{FeFe}]$-hydrogenases for specific applications or translate their catalytic principle into productive and durable synthetic mimics, detailed knowledge of the succession of turnover steps occurring at the $\mathrm{H}$-cluster is required. The binuclear metal cofactors of $[\mathrm{FeFe}]-$ and $[\mathrm{NiFe}]$-hydrogenases have been suggested to oxidize $\mathrm{H}_{2}$ by enhancing the acidity of $\mathrm{H}_{2}$ in the presence of a base, thus facilitating its heterolytic cleavage into a proton $\left(\mathrm{H}^{+}\right)$and hydride $\left(\mathrm{H}^{-}\right)$as a first intermediate step (Fig. 1) ${ }^{6-9}$.

For [NiFe]-hydrogenases, electron paramagnetic resonance spectroscopy showed that a bridging metal hydride was present in the paramagnetic $\mathrm{Ni}-\mathrm{C}$ state 6,7 , while an ultra-high $0.89 \AA$ resolution X-ray crystallography structure enabled the assignment of both, the proton and bridging hydride, in the first state following $\mathrm{H}_{2}$-binding $(\mathrm{Ni}-\mathrm{R})^{8}$. For algal-type $[\mathrm{FeFe}]-$ hydrogenases, a comparative density functional theory (DFT)/Xray absorption spectroscopy analysis indicated a bridging hydride $\left(\mu-\mathrm{H}^{-}\right)$in the double-reduced $\mathrm{H}_{\text {sred }}$ state ${ }^{10}$, albeit the importance of a $\mu-\mathrm{H}^{-}$state for fast catalytic turnover has been questioned. In fact, the terminal hydride $\left(\mathrm{t}-\mathrm{H}^{-}\right)$is thermodynamically less stable and more reactive compared to $\mu-\mathrm{H}^{-}$and would match the high turnover kinetics of [FeFe]-hydrogenases far better ${ }^{11-14}$. According to the current working model for the catalytic mechanism of $[\mathrm{FeFe}]$-hydrogenases ${ }^{1}$, binding of $\mathrm{H}_{2}$ to the oxidized active ready state $\left(\mathrm{H}_{\mathrm{ox}}\right)$ results in the heterolytic cleavage of $\mathrm{H}_{2}$, with $\mathrm{H}_{\text {hyd }}$ as the first intermediate. On deprotonation, $\mathrm{H}_{\text {hyd }}$ is converted into the rather stable $\mathrm{H}_{\text {sred }}$ state before two successive oxidation steps recycle $\mathrm{H}_{\text {ox }}$. A direct conversion of $\mathrm{H}_{\text {hyd }}$ into $\mathrm{H}_{\text {red }}$ has been proposed as well ${ }^{15}$. However, a terminal hydride has not been assigned to any of the known redox states ${ }^{10}$, nor has another catalytic wild-type state with the postulated $\mathrm{t}-\mathrm{H}^{-}$been reported. This implies that the kinetically relevant hydride state is a transient one and difficult to trap under steady-state conditions. Owing to the rules governing steady-state kinetics, which favour thermodynamically stable intermediates in catalysis, the direct characterization of transient states relies on the utilization of time-resolved approaches with stopped-flow or single-turnover set-ups ${ }^{16}$.

We take a different approach, exploiting the properties of steady-state kinetics and using Le Chatelier's principle to

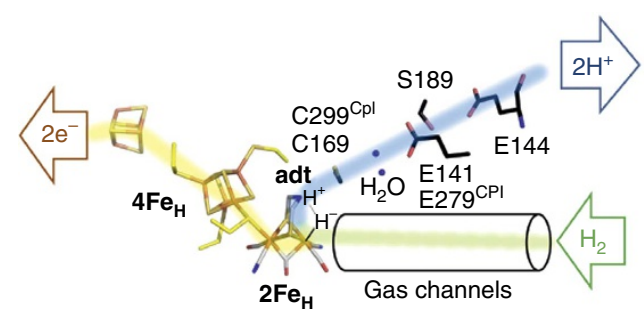

Figure 1 | Substrate/product transfer and heterolytic $\mathbf{H}_{\mathbf{2}}$ splitting in [FeFe]-hydrogenases. The electron-transfer path is shown in yellow, the PTP is depicted in blue. $\mathrm{H}_{2}$ is released from, or reaches the $2 \mathrm{Fe}_{\mathrm{H}}$ cluster through hydrophobic gas channels (green). At the catalytically pivotal $2 \mathrm{Fe}_{\mathrm{H}}$ site, the presumptive first step in the catalysis of $\mathrm{H}_{2}$ oxidation $\left(\mathrm{H}_{2}\right.$ heterolysis) is depicted, resulting in the unequal intermediates $\mathrm{H}^{+}$, binding at the adt-bridge (Lewis base) and $\mathrm{H}^{-}$, binding at $\mathrm{Fe}_{\mathrm{d}}$ (Lewis acid). selectively enrich the transient $\mathrm{t}_{-} \mathrm{H}^{-}$state in three different [FeFe]-hydrogenases: HydA1; $\mathrm{DdH}$; and $\mathrm{CpI}$, which cover the complete range of increasingly complex structured monomeric hydrogenase subtypes (M1-M3 $)^{17-20}$. In our experimental set-up, attenuated total reflection (ATR) Fourier-transform infrared (FTIR) spectroscopy is used to follow the population of different catalytic states. Compositional changes are monitored in the state-specific infrared signatures as a function of buffer/gas composition.

\section{Results}

Accumulation of $\mathbf{H}_{\text {hyd }}$ in wild-type [FeFe]-hydrogenases. Figure 2a depicts FTIR difference spectra of HydA1 film at $\mathrm{pH} 8$ recorded while changing the atmosphere from $\mathrm{N}_{2}$ to $\mathrm{H}_{2}$ (for details about the experimental setup see Supplementary Fig. 1). Negative bands mainly comprised the frequency pattern of $\mathrm{H}_{\mathrm{ox}}$ $\left(1,964 / 1,940 / 1,802 \mathrm{~cm}^{-1}\right)$. Positive bands included marker frequencies $1,915 / 1,891 \mathrm{~cm}^{-1}\left(\mathrm{H}_{\mathrm{red}}\right)$ and $1,953 / 1,918 / 1,882 \mathrm{~cm}^{-1}$ $\left(\mathrm{H}_{\text {sred }}\right)$, corresponding to earlier measurements with $\mathrm{H}_{2}$-purged HydA1 carried out in transmission FTIR systems ${ }^{21}$. On steadystate supply of substrate (that is, $\mathrm{H}_{2}$ ), the enzyme accumulates the apparently rather stable reduced intermediates $\mathrm{H}_{\text {red }}$ and $\mathrm{H}_{\text {sred }}$. However, bands at $1,978 / 1,960 / 1,860 \mathrm{~cm}^{-1}$ could be identified as minor contributions, indicating the presence of another state, which resembles the band pattern of $\mathrm{H}_{\text {trans }}$ in $\mathrm{DdH}\left(\mathrm{H}_{\text {trans }}\right.$-like state $)^{22}$ and was previously observed as a weak fraction of a complex band pattern in a sodium dithionite (NaDT)-treated HydA1 sample ${ }^{23}$. According to our working model, deprotonation should lead from the presupposed $\mathrm{H}_{\text {hyd }}$ to the reduced states (Fig. 2 b), and a plausible way to selectively enrich $\mathrm{H}_{\text {hyd }}$ would be a simultaneous increase in substrate $\left(\mathrm{H}_{2}\right)$ and product $\left(\mathrm{H}^{+}\right)$pressure (Fig. $2 \mathrm{~d}$ ). We therefore titrated HydA1 to $\mathrm{pH} 4$ before $\mathrm{H}_{2}$ exposure, enhancing the proton pressure by four orders of magnitude (Fig. 2c). The presence of a band at $1,891 \mathrm{~cm}^{-1}$ in the resulting difference spectrum hinted at a minor contribution of $\mathrm{H}_{\text {red }}$, while no $\mathrm{H}_{\text {sred }}$ could be detected. Instead, the $\mathrm{H}_{\text {trans }}$-like state represented the main fraction of our protein sample. No loss of cofactor was observed in the time frame of hours (Supplementary Fig. 2a,b), and the back-titration of HydA1 sample buffer from $\mathrm{pH} 4$ to $\mathrm{pH} 8$ clearly demonstrates a $\mathrm{pH}$-dependent reversibility of the indicated state transitions (Supplementary Fig. 2b,c). The same applies for $\mathrm{H}_{2}$-dependency at $\mathrm{pH} 4$ (Supplementary Fig. 2d). This bi-directionality is not compatible with the supposed $\mathrm{H}_{\text {trans }}$-like nature of the novel pattern $^{22}$. Therefore, we will refer to this redox state in the following as $\mathrm{H}_{\text {hyd }}$. Similar results were obtained when repeating this experiment with samples of native $\mathrm{DdH}$ and $\mathrm{CpI}$ as representatives of the other two major [FeFe]-hydrogenase subtypes, implying this state and behaviour to be general features of the [FeFe]-hydrogenase family (Supplementary Fig. 3).

The influence of proton-transfer efficiency. As the $\mathrm{H}_{2} / \mathrm{H}^{+}$ balance appears to affect the electronic configuration of the $\mathrm{H}$-cluster, alternative approaches were designed to enrich $\mathrm{H}_{\text {hyd }}$. HydAl sample was once more purged with $\mathrm{H}_{2}$ aerosol to first enrich the reduced states. When humidity was removed from the $\mathrm{H}_{2}$ gas stream, sample films reacted by rapid dehydration. As predicted, this as well leads to a loss of $\mathrm{H}_{\text {red }} / \mathrm{H}_{\text {sred }}$ in favour of the $1,978 / 1,960 /$ $1,860 \mathrm{~cm}^{-1}$ pattern (Supplementary Fig. $4 \mathrm{a}$ ) indicating that the loss of bulk water has a similar effect to lowering the buffer $\mathrm{pH}$, likely due to subsiding proton-transfer efficiency ${ }^{24}$ (Supplementary Fig. 4).

To verify that an interference with the PTP enhances the population of the $\mathrm{H}_{\text {hyd }}$ state under $\mathrm{H}_{2}$ exposure, we blocked the PTP in HydA1 and CPI via site-directed mutagenesis at two strictly conserved positions for each protein. Position 1 (C169 of 

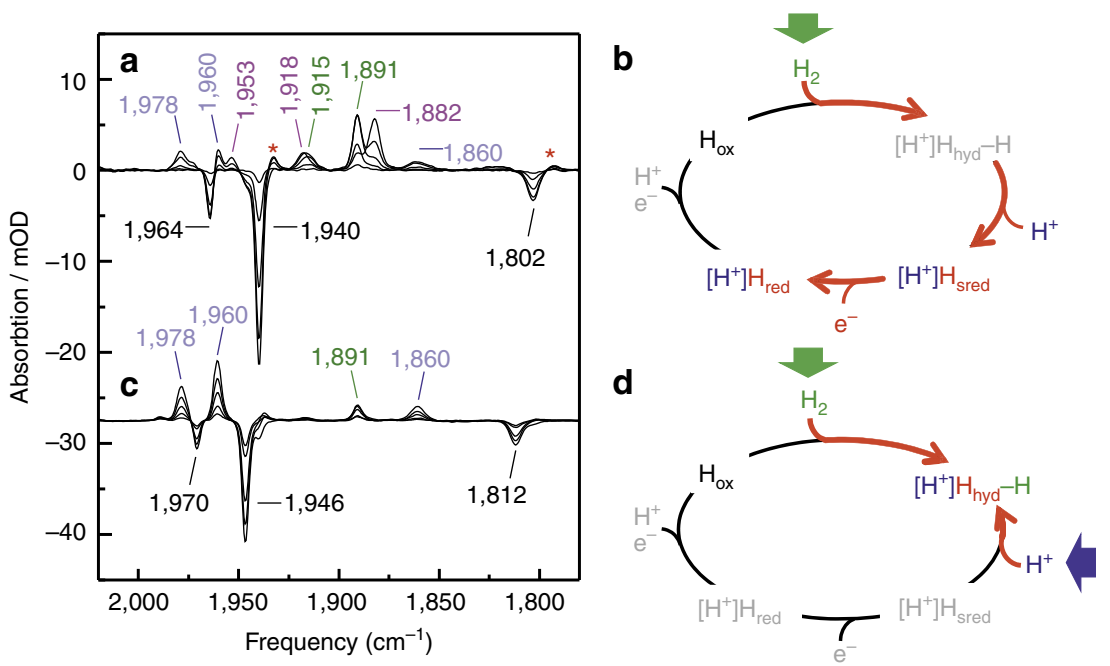

Figure 2 | Population of $\mathbf{H}_{\text {hyd }}$ in $\mathbf{H y d A 1}$ by simultaneously increasing $\mathbf{H}_{\mathbf{2}}$ and $\mathbf{H}^{+}$pressure. (a) ATR FTIR difference spectrum $\left(\mathrm{N}_{2} / \mathrm{pH} 8 \rightarrow \mathrm{H}_{2} / \mathrm{pH} 8\right)$, depicting the accumulation of the reduced states $\left(\mathrm{H}_{\text {red }} / \mathrm{H}_{\text {red }}\right.$ and $\left.\mathrm{H}_{\text {sred }}\right)$ in the catalytic cycle of HydA1 under $\mathrm{H}_{2}$ at pH 8. (c) ATR FTIR difference spectrum $\left(\mathrm{N}_{2} / \mathrm{pH} 8 \rightarrow \mathrm{H}_{2} / \mathrm{pH} 4\right)$ depicting the accumulation of $\mathrm{H}_{\text {hyd }}$ in the catalytic cycle of HydA1 under $\mathrm{H}_{2}$ at $\mathrm{pH}$ 4. Catalytic cycles (b,d) beside the corresponding spectra illustrate the shift in steady-state equilibrium depending on applied substrate and product pressures in the working model of the catalytic cycle, which comprises the already-characterized states $\mathrm{H}_{\mathrm{ox}}, \mathrm{H}_{\text {red }} / \mathrm{H}_{\text {red }}$ and $\mathrm{H}_{\text {sred }}$ and the missing $\mathrm{H}_{2}$-activated state $\left(\mathrm{H}_{\text {hyd }}\right)$. Peak labels for $\mathrm{H}_{\mathrm{ox}}$ are presented in black, for $\mathrm{H}_{\text {hyd }}$ in blue, for $\mathrm{H}_{\text {red }}$ in green and for $\mathrm{H}_{\text {sred }}$ in magenta (red asterisks: $\mathrm{H}_{\text {red }}$ ). For the complete state-specific $\mathrm{CN}^{-}-/ \mathrm{CO}^{-v i b r a t i o n a l ~ s p e c t r a ~ o f ~}$ HydA1 observed during sample analysis, see Supplementary Table 1. At pH 4, the vibrational signals of $\mathrm{H}_{\mathrm{ox}}$ were slightly shifted to higher frequencies (for more information see Supplementary Table 1, Hox-blue).

HydA1/C299 of CpI; Fig. 1), which was shown in earlier experimental data to be involved in catalytic proton transfer ${ }^{3,5}$, marks the most proximal position of the PTP to the $2 \mathrm{Fe}_{\mathrm{H}}$ subcluster, while position 2 (E141 of HydA1/E279 of CpI; Fig. 1) is situated more distant from the $\mathrm{H}$-cluster. An exchange to alanine almost completely abolished $\mathrm{H}_{2}$-release activity for all variants (Supplementary Fig. 6). To probe the structural integrity and unequivocally connect the monitored effects to an interrupted PTP, we solved the crystal structure of CpI E279A (Fig. 3). The $\mathrm{X}$-ray structure illustrates a fully intact $\mathrm{H}$-cluster and overall identical structural features compared to wild-type CpI (refs 19,25), with the exception of the clearly diminished electron density at position 279, which is in full accordance with an exchange from glutamate to alanine. As a consequence of this non-conservative exchange, the path of polar side chains is interrupted between $\mathrm{S} 319$ and the harnessed $\mathrm{H}_{2} \mathrm{O}$ molecule. Figure 4a,b shows the reaction of enzyme variants C169A of HydA1 and E279A of CpI towards $\mathrm{H}_{2}$ (black graph) at $\mathrm{pH} 8$. Similar to the effect of acidification or sample drying, the oxidized state is lost in favour of bands at $1,978 / 1,962 / 1,863 \mathrm{~cm}^{-1}$ or $1,985 / 1,970 / 1,858 \mathrm{~cm}^{-1}$, respectively.

We further exploited the effect of $\mathrm{H}_{\text {hyd }}$ accumulation as a consequence of PTP obstruction to elucidate the proposed role of the azadithiolate ligand in the heterolytic cleavage of $\mathrm{H}_{2}$. The earlierdescribed procedure of in vitro maturation allows for the replacement of the native $2 \mathrm{Fe}_{\mathrm{H}}$ site with derivatives such as odt$2 \mathrm{Fe}_{\mathrm{H}}$, which contains an oxodithiolate group $\left(\left(\mathrm{SCH}_{2}\right)_{2} \mathrm{O}\right.$,odt $)$ instead of the native azadithiolate $\left(\left(\mathrm{SCH}_{2}\right)_{2} \mathrm{NH} \text {, adt }\right)^{4,25,26}$. After in vitro maturation with odt $-2 \mathrm{Fe}_{\mathrm{H}}$ in presence of $\mathrm{H}_{2}, \mathrm{HydA1} 1^{\text {odt }}$ exhibits an infrared band pattern that strongly resembles $\mathrm{H}_{\text {hyd }}$ (refs 23,26). The oxidized state of $\mathrm{HydA} 1^{\text {odt }}$ was obtained via extensive purging with humidified $\mathrm{N}_{2}$. Subsequent exposure to $\mathrm{H}_{2}$ induced a decrease in the $\mathrm{H}_{\mathrm{ox}}$ pattern in favour of bands $1,980,1,962$ and $1868 \mathrm{~cm}^{-1}$ (Fig. 4c, black graph), however at a significantly lower rate compared to the corresponding experiment with wild-type HydA1.

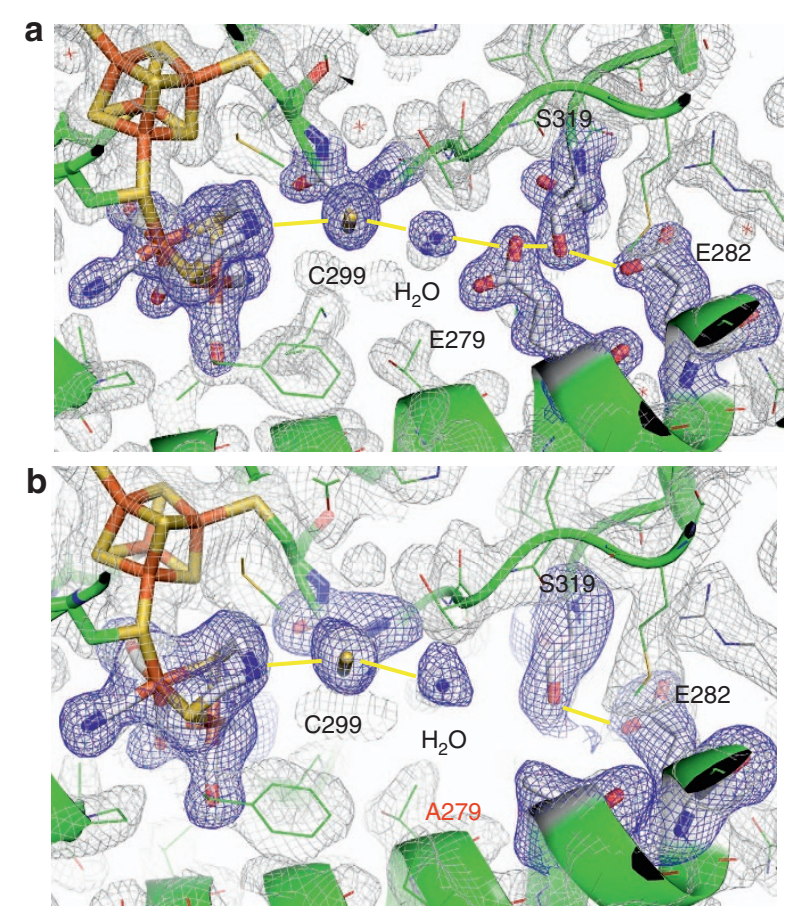

Figure 3 | Crystal structure of the PTP in wild-type Cpl and PTPdefective Cpl variant E279A. Stick models and simulated annealing omit $\mid \mathrm{Fo}-\mathrm{Fc}$ electron density maps (blue) of the $2 \mathrm{Fe}_{\mathrm{H}}$ cluster, and the amino-acid residues and the $\mathrm{H}_{2} \mathrm{O}$ molecules involved in proton transfer embedded in the 2Fo-Fc electron density maps (grey) of the $\mathrm{X}$-ray structures of $\mathrm{Cpl}$ wildtype $^{25}$ (a) and variant E279A (b). The presumed $\mathrm{H}^{+}$-transfer pathway is indicated in yellow. Crystal structure data for wild-type $\mathrm{Cpl}$ correspond to pdb database entry $4 X D C^{25}$. Details of the crystallographic data of E279A are summarized in Supplementary Table 2. For stereo view presentations see Supplementary Fig. 9. 

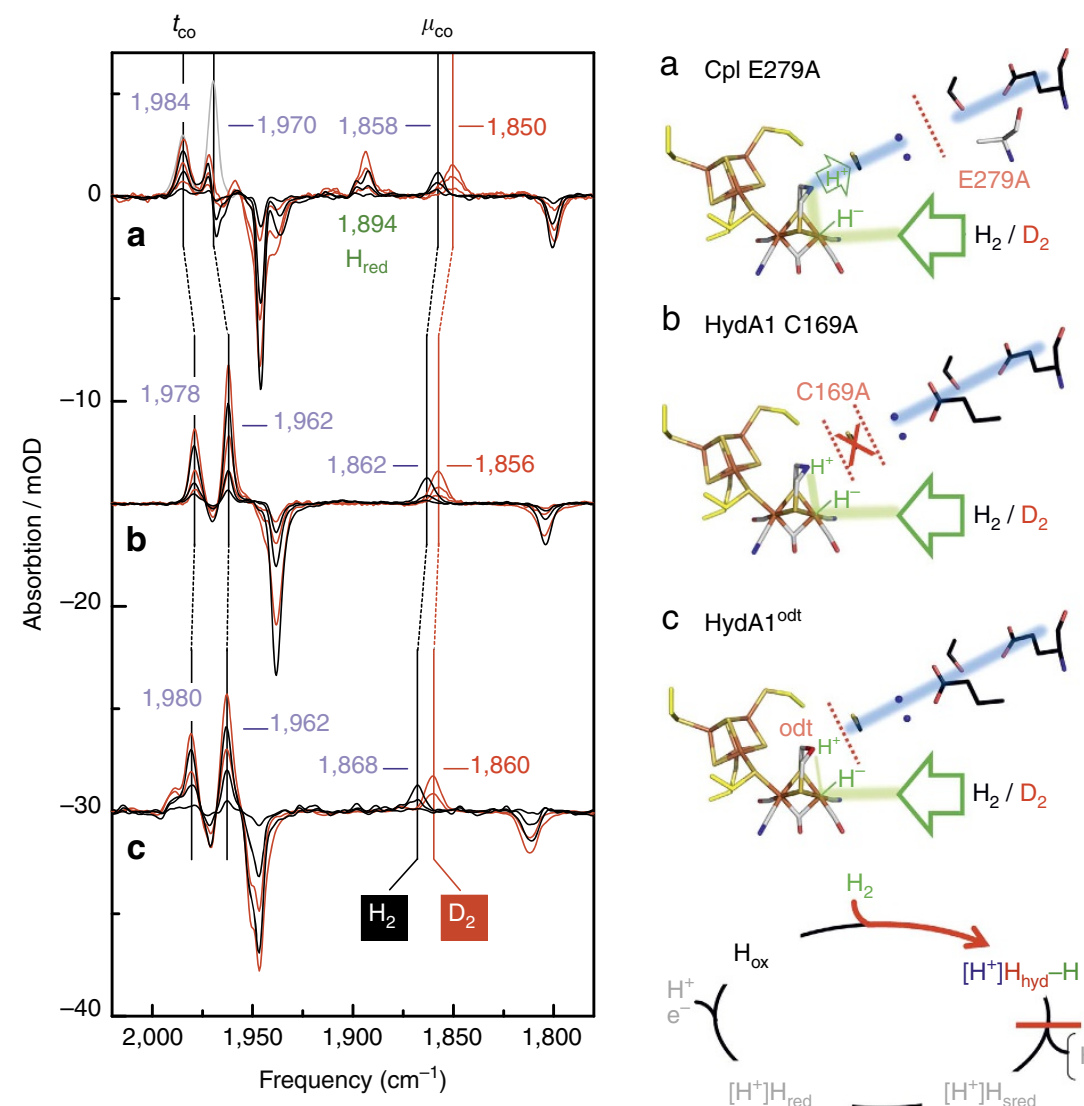

b HydA1 C169A
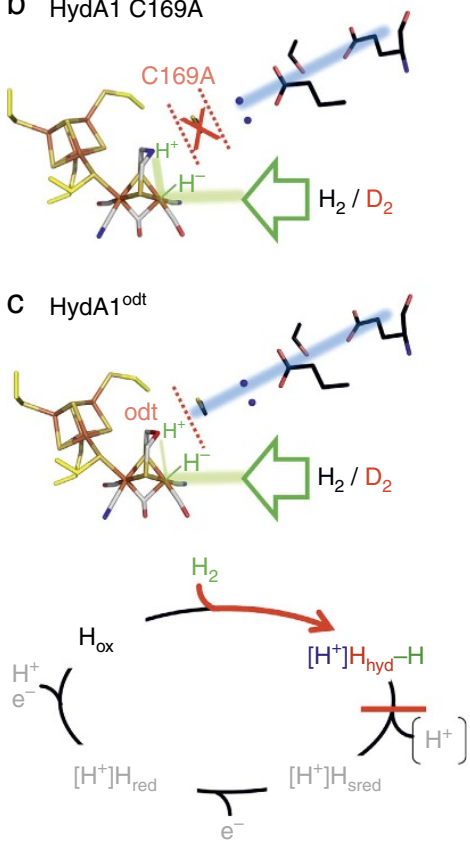

Figure 4 | Manipulating $\mathbf{H}^{+}$transfer traps the $\mathbf{H}_{\text {hyd }}$ state under $\mathbf{H}_{\mathbf{2}}$ or $\mathbf{D}_{\mathbf{2}}$ regardless of buffer $\mathbf{p H}$. Left: ATR FTIR difference spectra $\left(\mathrm{N}_{2} / \mathrm{pH} 8 \rightarrow \mathrm{H} \mathrm{H}_{2}\right.$ or $\mathrm{D}_{2} / \mathrm{pH} 8$ ) depicting the accumulation of $\mathrm{H}_{\text {hyd }}$ for variants of the PTP E279A (Cpl) (a) and C169A (HydA1) (b), as well as HydA $1^{\text {odt }}$ (c) under $\mathrm{H}_{2}$ or $\mathrm{D}_{2}$ at $\mathrm{pH}$ 8. The grey spectrum in a depicts the absolute absorption bands of $\mathrm{H}_{\text {hyd. }}$. Negative bands are assigned to $\mathrm{H}_{\mathrm{ox}}$ (Supplementary Table 1). Right: location of the corresponding PTP manipulation illustrated in a crystal structure model of $\mathrm{Cpl}$ (pdb ID: 4XDC). Accumulation of $\mathrm{H}_{\text {hyd }}$ under $\mathrm{D}_{2}$ (red spectra) does not affect the tCO-frequencies but induces a selective redshift for the $\mu \mathrm{CO}$ signal of $6-8 \mathrm{~cm}^{-1}$ in all analysed variants. For the complete state-specific $\mathrm{CN}^{-} / \mathrm{CO}-$ vibrational spectra observed during sample analysis, see Supplementary Table 1.

A terminal hydride in wild-type [FeFe]-hydrogenases. To confirm the presence of a terminal hydride $\left(\mathrm{t}-\mathrm{H}^{-}\right)$in $\mathrm{H}_{\text {hyd }}$ for wild-type hydrogenase and all examined variants, we probed the effect of an H/D isotope exchange on the FTIR band position of the bridging CO ligand, $\mu \mathrm{CO}$ (see Fig. 4, red graph, and Supplementary Figs 7 and 8 including Supplementary Note 1). Terminal hydride species on metal carbonyl complexes are vibrationally coupled with the ligand positioned in trans due to resonant frequencies ${ }^{27}$. Previously published DFT calculations on the H-cluster model of HydA1 variant C169S predict a selective 'redshift' of $6 \mathrm{~cm}^{-1}$ for the $\mu \mathrm{CO}$ frequency as a consequence of substituting a hydride for a deuteride species located trans to $\mu \mathrm{CO}$ (ref. 23). When switching the purging gas from $\mathrm{H}_{2}$ to $\mathrm{D}_{2}, \mathrm{CpI}$ E279A (Fig. 4a) and HydA1 C169A (Fig. 4b) showed a selective shift to lower energies by $5-6 \mathrm{~cm}^{-1}$ of the band at $1,860 \mathrm{~cm}^{-1}$, which corresponds to the stretching vibration of $\mu \mathrm{CO}$. A similar 'redshift' was observed for HydA $1^{\text {odt }}$ when the oxidized enzyme was extensively treated with $\mathrm{D}_{2}$ (Fig. $4 \mathrm{c}$ and Supplementary Fig. $7 \mathrm{~b}$ ). In Supplementary Fig. 8 we show spectra that document the H/D effect on wild-type HydA1 in presence of $\mathrm{pH} 4$ and $\mathrm{H}_{2} / \mathrm{D}_{2}$. This confirms the corresponding behaviour of the $\mathrm{H}_{\text {hyd }}$ state for all protein variants examined here.

\section{Discussion}

Le Chatelier's principle was applied to enrich the highly transient $\mathrm{H}$-cluster intermediate $\mathrm{H}_{\text {hyd }}$, which according to the current working model of catalytic $\mathrm{H}_{2}$ turnover is predicted to carry a terminal hydride species. By simultaneously enhancing substrate and product pressure, we accumulated $\mathrm{H}_{\text {hyd }}$ for three different wildtype $[\mathrm{FeFe}]$-hydrogenases. Interestingly, a nearly identical FTIR band pattern was observed in our earlier spectroscopic analysis of the largely inactive HydA1 PTP variant C169S (ref. 28). Using DFT calculations, Mulder et al. ${ }^{15,23}$ assigned this band pattern and redox species to a model of $\mathrm{C} 169 \mathrm{~S}$ that carried a terminal hydride at $\mathrm{Fe}_{\mathrm{d}}$ (Supplementary Note 1 and Supplementary Fig. 5).

Accumulation of $\mathrm{H}_{\text {hyd }}$ was also observed on decreasing the humidity level of the protein sample. Recently, we demonstrated that freeze-drying renders $[\mathrm{FeFe}]$-hydrogenase samples insensitive to $\mathrm{O}_{2}$ exposure ${ }^{24}$. Although $\mathrm{X}$-ray absorption spectroscopy data showed the formation of a stable $\mathrm{O}_{2}$ adduct at the $2 \mathrm{Fe}_{\mathrm{H}}$ site, $\mathrm{H}$-cluster degradation was not initiated, as opposed to hydrated enzyme in presence of $\mathrm{O}_{2}$ (ref. 29). DFT calculations suggested a protonation step mandatory for generating destructive reactive oxygen species ${ }^{30}$. Therefore, a lack of $\mathrm{H}^{+}$-transfer activity in the freeze-dried state appeared to be a plausible explanation for this effect and dehydration should have a similar effect as lowering the $\mathrm{pH}$. It can be speculated that the loss of bulk water, being the acceptor pool for exported protons, leads to an accumulation of protons in the PTP from the inside. Accordingly, low $\mathrm{pH}$ and dehydration both provide a counter pressure that prevents the $\mathrm{H}_{2}$-activated state from being deprotonated and proceeding to the reduced states (Supplementary Fig. 4b,c). 
The $\mathrm{N}_{2} / \mathrm{H}_{2}$ difference spectra of site-directed exchange variants of HydA1 and CPI targeting positions C169/C299 and E141/E279 clearly demonstrate how the disrupted proton transport stabilizes the $\mathrm{H}_{\text {hyd }}$ state regardless of buffer $\mathrm{pH}$. This highlights that the transient character of $\mathrm{H}_{\text {hyd }}$ essentially depends on a functional catalytic proton transfer, just as predicted from the working model (Figs 1 and 2). In return, the analogous behaviour of cysteine and glutamate variants provides experimental proof for the involvement of the median glutamic acid residue (E141 ${ }^{\mathrm{HydA1}}$ / $\left.\mathrm{E} 279^{\mathrm{CPI}}\right)$ in the proton-transfer mechanism of [FeFe]-hydrogenases. In future mutagenesis studies on the PTP of [FeFe]hydrogenases, accumulation of $\mathrm{H}_{\text {hyd }}$ can be regarded as an experimental indicator for the involvement of peptide positions in the catalytic $\mathrm{H}^{+}$transfer.

The relevance of the bridgehead position of the $2 \mathrm{Fe}_{\mathrm{H}}$ subcluster for catalytic proton transfer was clearly demonstrated by the fact that cofactor variant $\mathrm{HydA} 1^{\text {odt }}$ could be trapped in $\mathrm{H}_{\text {hyd }}$ under $\mathrm{H}_{2}$ independent of the $\mathrm{pH}$, thus confirming the results of earlier studies, which pointed out the essential role of the native adt ligand as a proton relay to the substrate-binding site at $\mathrm{Fe}_{\mathrm{d}}$. The fact that $\mathrm{H}_{2}$ exposure of HydA1 $1^{\text {odt }}$ results in $\mathrm{H}_{\text {hyd }}$ accumulation suggests that the ether bridgehead of odt is capable to serve as a Lewis base and supports heterolytic $\mathrm{H}_{2}$ cleavage. This reflects earlier investigations of Barton et al. ${ }^{31}$ which demonstrated in a comparative study, including different diiron complexes that the weakly basic ether group of odt can assist in proton relay during $\mathrm{H}_{2}$ evolution ${ }^{31}$. However, in contrast to C169A and E279A, the $\mathrm{H}_{\text {hyd }}$ spectrum of HydA $1^{\text {odt }}$ could only be regained very slowly in presence of $\mathrm{H}_{2}$. While all examined enzyme variants exhibited an impaired proton transfer, for C169A and E279A the defect was restricted to the $\mathrm{H}^{+}$transfer across the protein shell (Fig. 4). In case of $\mathrm{HydAl}^{\text {odt }}$, the impairment already affected proton abstraction during $\mathrm{H}_{2}$ heterolysis. This finding experimentally verifies the hypothesis that the pending amine group in the native adt ligand significantly enhances the rate of heterolytic $\mathrm{H}_{2}$ cleavage $^{31}$. The selective shift of the $\mu \mathrm{CO}$ band observed in $\mathrm{H}_{\text {hyd }}$ on $\mathrm{H} / \mathrm{D}$ exchange suggests the presence of a terminal hydride ligand for all PTP variants and catalytically competent wild-type enzymes examined here.

In addition, two recently published studies independently demonstrated a terminal hydride for inactive HydA1 variants assigned to the presumptive $\mathrm{H}_{\text {hyd }}$ state. Reijerse et al. ${ }^{32}$ reported the direct detection of $\mathrm{Fe}_{\mathrm{d}}-\mathrm{H}$ bending vibrations via nuclear resonance vibrational spectroscopy of a terminal hydride species in $\mathrm{HydA} 1^{\text {odt }}$ after isolation under $\mathrm{H}_{2}$. This is in good agreement with our real-time analysis of $\mathrm{HydA} 1^{\text {odt }}$. Furthermore, Mulder et al. ${ }^{15}$ applied electron paramagnetic resonance and Mössbauer spectroscopy to provide experimental support for the presence of a metal hydride species in HydA1 variant C169S, which largely adopted $\mathrm{H}_{\text {hyd }}$ on supplementation with $\mathrm{NaDT}$. Well in agreement with electrochemistry studies on HydA1 under turnover conditions ${ }^{14}$, the authors determined a $\mathrm{H}_{\text {hyd }}$ transition potential close to the $\mathrm{H}_{2} / \mathrm{H}^{+}$redox couple. This argues in favour of the relevance of $\mathrm{H}_{\text {hyd }}$ in the catalytic cycle.

Both HydA1 C169S and HydA1 ${ }^{\text {odt }}$ have been shown to be largely inactive $4,15,23,25,26,28,32$, and a definite proof for the catalytic relevance of $\mathrm{H}_{\text {hyd }}$ can only be given by monitoring the succession of states during catalysis at sub-turnover time resolution as previously done for $[\mathrm{NiFe}]$-hydrogenase ${ }^{16}$. However, this work strongly suggests that $\mathrm{H}_{\text {hyd }}$, as identified by Mössbauer and nuclear resonance vibrational spectroscopy, corresponds to the first transient state in the catalytic mechanism of $\mathrm{H}_{2}$ oxidation and is shared by all major subtypes of [FeFe]-hydrogenases. It is therefore plausible to assume that we successfully accumulated a state carrying a terminal hydride ligand in native $[\mathrm{FeFe}]$-hydrogenases. In response to modulating substrate and product concentrations $\left(\mathrm{H}^{+} / \mathrm{H}_{2}\right)$, accumulation of $\mathrm{H}_{\text {hyd }}$ was found to be fully reversible showing that $\mathrm{H}_{\text {hyd }}$ is no artificial dead-end state but part of the dynamic redox equilibrium typically occurring in the catalytically competent enzyme. All available data strongly suggest that $\mathrm{H}_{\text {hyd }}$ is indeed the missing link in the catalytic mechanism of [FeFe]-hydrogenases.

\section{Methods}

Site-directed mutagenesis of HydA1 and Cpl. Plasmids pET21b-HydA1Cr and pET21b-CpI were used as templates for site-directed mutagenesis, which was performed according to the QuikChange-PCR protocol published by Zheng et al. ${ }^{33}$ For generating the constructs encoding HydA1 variants C169A, C169S and E141A, the $5^{\prime}$-overlapping mismatch primer pairs $5^{\prime}$-CAGCGCGTGTCCGGGCTGG ATTGC-3'/ $5^{\prime}$-CCGGACACGCGCTGGTAAACATCGG-3' ${ }^{\prime}$ 5'-CAGCTCATG TCCGGGCTGGATTGC- $3^{\prime} / 5^{\prime}$-CCGGACATGAGCTGGTAAACATC-GG- $3^{\prime}$ and $5^{\prime}$-CATCATGGAAGCGGGCAGCGAACTGCTGCATCGTC-3' $/ 5^{\prime}$-GCAGTTCGCTGCCCGCTTCCATGATGGTCAGATCC-3' were used, respectively.

For substitutions C299A and E279A within the polypeptide of CpI, primer pairs $5^{\prime}$-CCTCTGCGTGCCCAGGTTGGGTACGTC-3'/5' -CCTGGGCACGCAGAGG TAAACATT-GGGAAAGGG- $3^{\prime}$ and $5^{\prime}$-CCAGTTCGGTAGCCGCTTCCATAA TGGTCATATC-3'/ $5^{\prime}$-TG-GAAGCGGCTACCGAACTGGTTCAACG were utilized.

Heterologous expression of HydA1 and Cpl proteins. The original plasmids pET21b-HydA1Cr and pET21b-CpI and their mutagenesis constructs were used for the heterologous expression of wild-type enzymes and variants of HydAl and CpI (refs 4,25,34,35). Apo-forms of CpI and HydAl (lacking $2 \mathrm{Fe}_{\mathrm{H}}$ ) were expressed anaerobically in Escherichia coli strain BL21 $\Delta$ iscR (ref. 36). Cells first grew aerobically in lysogeny broth (LB) medium pH $7.4(0.1 \mathrm{M}$ morpholineopropanesulfonic acid (Mops)- $\mathrm{NaOH}$ ) supplemented with $5 \mathrm{gl}^{-1}$ glucose and $2 \mathrm{mM}$ ammonium iron citrate until an OD600 of 0.35-0.6 was reached. Before switching to anaerobic cultivation, the culture was flush with $\mathrm{N}_{2}$ for 30 min to remove residual $\mathrm{O}_{2}$ and supplemented with $25 \mathrm{mM}$ sodium fumarate. Induction of gene expression was initiated by adding $5 \mathrm{mM}$ cysteine and $0.5 \mathrm{mM}$ $\beta$-D-1-thiogalactopyranoside. Cells were collected after $16-24 \mathrm{~h}$ expression via centrifugation.

Purification of [FeFe]-hydrogenase apo-proteins. The apo-proteins of wild-type and mutant forms of $\mathrm{HydAl}$ and $\mathrm{CpI}$, containing the $4 \mathrm{Fe}_{\mathrm{H}}$ subcluster but lacking the $2 \mathrm{Fe}_{\mathrm{H}}$ moiety, were expressed under anaerobic conditions in E. coli strain BL21 $\Delta \mathrm{iscR}$ as described earlier ${ }^{4,34,36}$. After cell disruption via ultrasonication and the separation of the soluble proteins from the cell debris by ultracentrifugation and subsequent filtering (pore size $0.2 \mu \mathrm{m}$ ), we exploited the C-terminally fused Streptag-II sequence (WSHPQFEK) for protein purification, performing affinity chromatography with Strep-Tactin Superflow resin (IBA GmbH) in $100 \mathrm{mM}$ Tris$\mathrm{HCl}$ buffer ( $\mathrm{pH}$ 8) supplemented with $2 \mathrm{mM} \mathrm{NaDT}$. Protein purity was verified by SDS-PAGE and protein concentration determined via Bradford assay (BioRad).

Synthesis of $\mathbf{2} \mathbf{F e}_{\mathbf{H}}$ cofactor complexes. The native-like $2 \mathrm{Fe}_{\mathrm{H}}$-cofactor-mimic complex $\left[\mathrm{Fe}_{2}\left[\mu-\left(\mathrm{SCH}_{2}\right)_{2} \mathrm{NH}\right](\mathrm{CN})_{2}(\mathrm{CO})_{4}\right]\left[\mathrm{Et}_{4} \mathrm{~N}\right]_{2}\left(\right.$ adt- $\left.2 \mathrm{Fe}_{\mathrm{H}}\right)$ and its odt derivative $\left[\mathrm{Fe}_{2}\left[\mu-\left(\mathrm{SCH}_{2}\right)_{2} \mathrm{O}\right](\mathrm{CN})_{2}(\mathrm{CO})_{4}\right]\left[\mathrm{Et}_{4} \mathrm{~N}\right]_{2}\left(\right.$ odt- $\left.2 \mathrm{Fe}_{\mathrm{H}}\right)$ were synthesized according to literature procedures 25

In vitro maturation. To obtain the fully equipped holoprotein, heterologously expressed wild-type and mutant apo-proteins of HydAl and $\mathrm{CpI}$ were maturated in vitro by adding adt- $2 \mathrm{Fe}_{\mathrm{H}}\left(\right.$ odt- $2 \mathrm{Fe}_{\mathrm{H}}$ ) to a 10 -fold excess in $0.1 \mathrm{M} \mathrm{K}_{2} \mathrm{HPO}_{4}$ / $\mathrm{KH}_{2} \mathrm{PO}_{4}$ buffer (pH 6.8), supplemented with $2 \mathrm{mM}$ NaDT. To ensure complete sample maturation, the reaction mix was incubated for $1 \mathrm{~h}$ at room temperature. The resulting holoproteins were cleaned from surplus $2 \mathrm{Fe}_{\mathrm{H}}$ complex by sizeexclusion chromatography using NAP 5 columns of GE Healthcare and concentrated in Amicon Ultra centrifugal filters $30 \mathrm{~K}$ (Millipore). Afterwards, methyl viologen-specific $\mathrm{H}_{2}$ production activity was determined to assess catalytic competence.

In vitro assay to determine $\mathbf{H}_{\mathbf{2}}$ production activity. $\mathrm{H}_{2}$ production activities have been determined in vitro for wild-type and mutant proteins using $0.2 \mu \mathrm{g} \mathrm{ml}^{-1}$ of in vitro maturated [FeFe]-hydrogenase in $2 \mathrm{ml}$ of $100 \mathrm{mM}$ postassium phosphate buffer, pH 6.8, supplemented with $100 \mathrm{mM} \mathrm{NaDT}$ and $10 \mathrm{mM}$ methyl viologen. Suba-seal vessels were sealed with stoppers, degassed for 5 min with $100 \%$ Argon and incubated for $20 \mathrm{~min}$ in a shaking water bath adjusted to $37^{\circ} \mathrm{C}$. For product quantification, $400 \mu \mathrm{l}$ of sample head-space was analysed via gas chromatography (Shimadzu GC 2010). When enzyme activity was below the detection limit, the assay was repeated with a 10 -fold increased enzyme concentration $\left(2 \mu \mathrm{g} \mathrm{ml}^{-1}\right)$.

Crystallization and structure analysis of Cpl variant E279A. Using a 1:1 mix of E279A holoprotein $\left(10 \mathrm{mg} \mathrm{ml}^{-1}\right)$ and reservoir solution $(0.1 \mathrm{M} \mathrm{MES}, \mathrm{pH} 6$, 
supplemented with $0.4 \mathrm{M} \mathrm{MgCl}_{2}, 24 \%$ polyethylene glycol and $16 \%$ glycerol) in a hanging drop vapour diffusion set-up, single cuboid-shaped crystals of brownish colour were identified after $2-4$ days at $277 \mathrm{~K}$ under anaerobic conditions. The selected protein crystal was mounted into a CryoLoop (Hampton Research) and flash-frozen in liquid $\mathrm{N}_{2}$. Diffraction data were collected at $100 \mathrm{~K}$ at beamline ID23-2 of the ESRF in Grenoble, France and processed using the software package $\mathrm{XDS}^{37}$. Molecular replacement and structure optimization were achieved with the software packages PHENIX ${ }^{38}$ and $\operatorname{Coot}^{39}$. For details on crystallographic data of CpI E279A, see Supplementary Table 2.

Infrared spectroscopy. All FTIR spectroscopy was conducted on a rapid-scan Tensor 27 spectrometer (Bruker Optik, Germany) equipped with a three-reflection ZnSe/silicon crystal ATR cell (Smith Detection, USA). The spectrometer was situated in an anaerobic gas chamber (Coy Laboratories, USA) in a water-free atmosphere of typically $99 \% \mathrm{~N}_{2}$ and $1 \% \mathrm{H}_{2}$. Supplementary Fig. 1 depicts the process flow diagram of the experimental set-up. Approximately 5 bar nitrogen carrier gas of ultra-high purity (5.0) was provided by a PN1450 nitrogen generator (Inmatec, Germany). The exact amount of $\mathrm{N}_{2}$ was adjusted with a digital SmartTrak mass flow controller (MFC, Sierra, USA). Molecular $\mathrm{H}_{2}\left(\mathrm{H}_{2}\right.$ 5.0, Linde, Germany) was injected separately via a second flow controller to create a welldefined mixture. The gas passed a 200 mbar check valve to protect the flow controllers from humidity. Afterwards, two sequential wash bottles $\left(\mathrm{H}_{2} \mathrm{O}\right.$ and miscellaneous content, for example, buffer) could be switched into the gas stream. A bypass loop allowed for an adjustable proportion of the gas to bypass the wash bottles entirely or to run through the liquid volume to create a mix of carrier gas, water vapour and microscopic drops of liquid water (aerosol). The aerosol stream was fed to a customized polychlorotrifluoroethylene (PCTFE) gas cell, screwed gastight onto the ATR crystal plate. An exit line eventually guided the aerosol to a gas dump (fume). The PCTFE gas cell was equipped with three inlets and a manometer (not shown in Supplementary Fig. 1). Directly over the silicon crystal of the ATR unit, a cylindrical cavity joined all inlets. A gas-tight lid was screwed on top of the gas cell and allowed irradiation via an acrylic glass window. At this position, an infrared- or ultraviolet/visible-transparent window with protein sample could be adjusted into the aerosol stream. Thus, transmission samples for, for example, ultraviolet/visible or Raman spectroscopy could be prepared under the same conditions as monitored via the ATR silicon crystal. All spectra were recorded with $80 \mathrm{kHz}$ scanning velocity, at a spectral resolution of $1 \mathrm{~cm}^{-1}$, and varying extent of co-additions. All pH titrations were performed with citrate buffer (SSC).

Data availability. The atomic coordinates and factors for the reported crystal structure for CpI variant E279A have been deposited with the Protein Data Bank (PDB) under accession code 5LA3. Further data supporting the findings of this study are available within the article and its Supplementary Information file and from the corresponding authors on reasonable request.

\section{References}

1. Lubitz, W., Ogata, H., Rudiger, O. \& Reijerse, E. Hydrogenases. Chem. Rev. 114, 4081-4148 (2014)

2. Cornish, A. J., Gartner, K., Yang, H., Peters, J. W. \& Hegg, E. L. Mechanism of proton transfer in [FeFe]-hydrogenase from Clostridium pasteurianum. J. Biol. Chem. 286, 38341-38347 (2011).

3. Morra, S. et al. Site saturation mutagenesis demonstrates a central role for cysteine 298 as proton donor to the catalytic site in $\mathrm{CaHydA}$ [FeFe]hydrogenase. PLoS ONE 7, e48400 (2012).

4. Berggren, G. et al. Biomimetic assembly and activation of [FeFe]-hydrogenases. Nature 499, 66-69 (2013).

5. Silakov, A., Wenk, B., Reijerse, E. \& Lubitz, W. (14)N HYSCORE investigation of the H-cluster of [FeFe] hydrogenase: evidence for a nitrogen in the dithiol bridge. Phys. Chem. Chem. Phys. 11, 6592-6599 (2009).

6. Brecht, M., van Gastel, M., Buhrke, T., Friedrich, B. \& Lubitz, W. Direct detection of a hydrogen ligand in the $[\mathrm{NiFe}]$ center of the regulatory $\mathrm{H} 2$-sensing hydrogenase from Ralstonia eutropha in its reduced state by HYSCORE and ENDOR spectroscopy. J. Am. Chem. Soc. 125, 13075-13083 (2003).

7. Foerster, S. et al. Single crystal EPR studies of the reduced active site of [NiFe] hydrogenase from Desulfovibrio vulgaris Miyazaki F. J. Am. Chem. Soc. 125, 83-93 (2003).

8. Ogata, H., Nishikawa, K. \& Lubitz, W. Hydrogens detected by subatomic resolution protein crystallography in a [NiFe] hydrogenase. Nature 520, 571-574 (2015).

9. Schilter, D., Camara, J. M., Huynh, M. T., Hammes-Schiffer, S. \& Rauchfuss, T. B. Hydrogenase enzymes and their synthetic models: the role of metal hydrides. Chem. Rev. 116, 8693-8749 (2016).

10. Chernev, P. et al. Hydride binding to the active site of [FeFe]-hydrogenase. Inorg. Chem. 53, 12164-12177 (2014).

11. Bruschi, M. et al. Influence of the $[2 \mathrm{Fe}] \mathrm{H}$ subcluster environment on the properties of key intermediates in the catalytic cycle of $[\mathrm{FeFe}]$ hydrogenases: hints for the rational design of synthetic catalysts. Angew. Chem. Int. Ed. 48, 3503-3506 (2009).

12. Carroll, M. E., Barton, B. E., Rauchfuss, T. B. \& Carroll, P. J. Synthetic models for the active site of the $[\mathrm{FeFe}]$-hydrogenase: catalytic proton reduction and the structure of the doubly protonated intermediate. J. Am. Chem. Soc. 134, 18843-18852 (2012).

13. Finkelmann, A. R., Stiebritz, M. T. \& Reiher, M. Inaccessibility of the $\mu$-hydride species in $[\mathrm{FeFe}]$ hydrogenases. Chem. Sci. 5, 215-221 (2014).

14. Hexter, S. V., Grey, F., Happe, T., Climent, V. \& Armstrong, F. A. Electrocatalytic mechanism of reversible hydrogen cycling by enzymes and distinctions between the major classes of hydrogenases. Proc. Natl Acad. Sci. USA 109, 11516-11521 (2012).

15. Mulder, D. W., Guo, Y., Ratzloff, M. W. \& King, P. W. Identification of a catalytic iron-hydride at the $\mathrm{H}$-cluster of [FeFe]-hydrogenase. J. Am. Chem. Soc. 139, 83-86 (2017).

16. Greene, B. L., Wu, C. H., McTernan, P. M., Adams, M. W. \& Dyer, R. B. Proton-coupled electron transfer dynamics in the catalytic mechanism of a [NiFe]-hydrogenase. J. Am. Chem. Soc. 137, 4558-4566 (2015).

17. Mulder, D. W. et al. Stepwise [FeFe]-hydrogenase H-cluster assembly revealed in the structure of HydA(DeltaEFG). Nature 465, 248-251 (2010).

18. Nicolet, Y., Piras, C., Legrand, P., Hatchikian, C. E. \& Fontecilla-Camps, J. C. Desulfovibrio desulfuricans iron hydrogenase: the structure shows unusual coordination to an active site Fe binuclear center. Structure 7, 13-23 (1999).

19. Peters, J. W., Lanzilotta, W. N., Lemon, B. J. \& Seefeldt, L. C. X-ray crystal structure of the Fe-only hydrogenase (CpI) from Clostridium pasteurianum to 1.8 angstrom resolution. Science 282, 1853-1858 (1998).

20. Winkler, M., Esselborn, J. \& Happe, T. Molecular basis of [FeFe]-hydrogenase function: an insight into the complex interplay between protein and catalytic cofactor. Biochim. Biophys. Acta 1827, 974-985 (2013).

21. Adamska, A. et al. Identification and characterization of the 'super-reduced' state of the $\mathrm{H}$-cluster in [FeFe] hydrogenase: a new building block for the catalytic cycle? Angew. Chem. Int. Ed. 51, 11458-11462 (2012).

22. Roseboom, W., De Lacey, A. L., Fernandez, V. M., Hatchikian, E. C. \& Albracht, S. P. The active site of the [FeFe]-hydrogenase from Desulfovibrio desulfuricans. II. Redox properties, light sensitivity and CO-ligand exchange as observed by infrared spectroscopy. J. Biol. Inorg. Chem. 11, 102-118 (2006).

23. Mulder, D. W. et al. Investigations on the role of proton-coupled electron transfer in hydrogen activation by [FeFe]-hydrogenase. J. Am. Chem. Soc. 136, 15394-15402 (2014).

24. Noth, J. et al. Lyophilization protects [FeFe]-hydrogenases against $\mathrm{O} 2$-induced H-cluster degradation. Sci. Rep. 5, 13978 (2015).

25. Esselborn, J. et al. A structural view of synthetic cofactor integration into [FeFe]-hydrogenases. Chem. Sci. 7, 959-968 (2016).

26. Siebel, J. F. et al. Hybrid [FeFe]-hydrogenases with modified active sites show remarkable residual enzymatic activity. Biochemistry 54, 1474-1483 (2015).

27. Kaesz, H. D. \& Saillant, R. B. Hydride complexes of the transition metals. Chem. Rev. 72, 231-281 (1972).

28. Knorzer, P. et al. Importance of the protein framework for catalytic activity of [FeFe]-hydrogenases. J. Biol. Chem. 287, 1489-1499 (2012).

29. Stripp, S. T. et al. How oxygen attacks $[\mathrm{FeFe}]$ hydrogenases from photosynthetic organisms. Proc. Natl Acad. Sci. USA 106, 17331-17336 (2009).

30. Bruska, M. K., Stiebritz, M. T. \& Reiher, M. Regioselectivity of H cluster oxidation. J. Am. Chem. Soc. 133, 20588-20603 (2011).

31. Barton, B. E., Olsen, M. T. \& Rauchfuss, T. B. Aza- and oxadithiolates are probable proton relays in functional models for the [FeFe]-hydrogenases. J. Am. Chem. Soc. 130, 16834-16835 (2008).

32. Reijerse, E. J. et al. Direct observation of an iron-bound terminal hydride in [FeFe]-hydrogenase by nuclear resonance vibrational spectroscopy. J. Am. Chem. Soc. 139, 4306-4309 (2017).

33. Zheng, L., Baumann, U. \& Reymond, J. L. An efficient one-step site-directed and site-saturation mutagenesis protocol. Nucleic Acids Res. 32, e115 (2004).

34. Esselborn, J. et al. Spontaneous activation of [FeFe]-hydrogenases by an inorganic [2Fe] active site mimic. Nat. Chem. Biol. 9, 607-609 (2013).

35. Kuchenreuther, J. M. et al. High-yield expression of heterologous [FeFe] hydrogenases in Escherichia coli. PLoS ONE 5, el5491 (2010).

36. Akhtar, M. K. \& Jones, P. R. Deletion of iscR stimulates recombinant clostridial $\mathrm{Fe}-\mathrm{Fe}$ hydrogenase activity and $\mathrm{H} 2$-accumulation in Escherichia coli BL21(DE3). Appl. Microbiol. Biotechnol. 78, 853-862 (2008).

37. Kabsch, W. XDS. Acta Crystallogr. D Biol. Crystallogr. 66, 125-132 (2010).

38. Adams, P. D. et al. PHENIX: a comprehensive Python-based system for macromolecular structure solution. Acta Crystallogr. D Biol. Crystallogr. 66, 213-221 (2010).

39. Emsley, P., Lohkamp, B., Scott, W. G. \& Cowtan, K. Features and development of Coot. Acta Crystallogr. D Biol. Crystallogr. 66, 486-501 (2010).

\section{Acknowledgements}

T.H. and M.W. gratefully acknowledge financial support from the Deutsche Forschungsgemeinschaft Cluster of Excellence RESOLV (EXC1069), the Volkswagen 
Foundation (LigH2t) and the EU (Sun2Chem). M.S. and S.T.S. thank the International Max Plank Research School (IMPRS) on Multiscale Biosystems and the Focus Area NanoScale (Freie Universität Berlin) for financial support. J.D. acknowledges support by the China Scholarship Council (CSC). U.-P.A. and F.W. are grateful for financial support by the Funds of the Chemical Industry (Liebig grant to U.-P.A.) and the Deutsche Forschungsgemeinschaft (Emmy Noether grant to U.-P.A., AP242/2-1). We further thank J. Fontecilla-Camps for providing a sample of DdH protein, and the staff at beam line ID23-2 at the ESRF, France, for their help during data collection. We gratefully acknowledge the support of Dr Anne Sawyer during the text revision process.

\section{Author contributions}

M.W., S.T.S. and T.H. designed research; M.W., S.T.S. and T.H. wrote the manuscript; U.-P.A. and F.W. synthesized the $2 \mathrm{Fe}_{\mathrm{H}}$-adt/-odt complexes for in vitro maturation; J.D. and M.W. produced, purified and maturated the wild-type and mutant proteins of HydA1 and CpI; S.T.S. and M.S. performed and designed ATR FTIR experiments; J.D., E.H. and J.E. performed or contributed to protein crystallization and X-ray structure analysis.

\section{Additional information}

Supplementary Information accompanies this paper at http://www.nature.com/ naturecommunications

Competing interests: The authors declare no competing financial interests.

Reprints and permission information is available online at http://npg.nature.com/ reprintsandpermissions/

How to cite this article: Winkler, M. et al. Accumulating the hydride state in the catalytic cycle of [FeFe]-hydrogenases. Nat. Commun. 8, 16115 doi: 10.1038/ncomms16115 (2017).

Publisher's note: Springer Nature remains neutral with regard to jurisdictional claims in published maps and institutional affiliations.

(c) (i)

\section{ap}$$
\text { ind }
$$ \\ ind} h://creativecommons.org/ licenses/by/4.0/

(C) The Author(s) 2017 